\title{
Complex Ovarian Cyst
}

National Cancer Institute

\section{Source}

National Cancer Institute. Complex Ovarian Cyst. NCI Thesaurus. Code C5215.

A cystic lesion that arises from the ovary. It is characterized by the presence of cystic spaces that contain fluid and a solid tissue component. 